\title{
Developing an ontology for automated scene creation
}

\author{
Diana Contraş, Alina Pintescu and Honoriu VăLean
}

\section{ABSTRACT.}

This article presents an ontology meant to be used by algorithms for automated creation of scenes. At any time and in any place we encounter scenes: in plays, in paintings, in film frames, at hospitals, at police stations, at schools, at restaurants, at stores, everywhere. Depending on where it is located, a scene can contain more types of elements: backgrounds, objects, characters connected through their spatial relationships. Our intention is to offer the posibility of realizing many combinations of the chosen elements in order to obtain the wated scene. In practice is difficult to obtain such a result, that is why we intend to design an automatic system, which will automatically generate the scenes. The possible elements of scenes together with their relationships are grouped in an ontology which is presented in this article.

\section{REFERENCES}

[1] Alatrish, E. S., Comparison of Ontology Editors, e-RAF Journal on Computing, Vol. No. 4, 2012

[2] Colton, S., Automatic Invention of Fitness Functions with Application to Scene Generation, Department of Computing, Imperial College, London, 2008

[3] Ekárt, A., Sharma, D. and Chalakov, S., Modelling human preference in evolutionary art, Springer Berlin Heidelberg, 2011, 303-312

[4] Gómez-Pérez, A. and Fernández-López, M., Overview and analysis of methodologies for building ontologies, The Knowledge Engineering Review, 2002

[5] Gómez-Pérez, A., Fernández-López, M. and Corcho, O., Ontological Engineering: With Examples from the Areas of Knowledge Management, Ecommerce and the Semantic Web, Springer, 2004

[6] Gruber, T. R., A Translation Approach to Portable Ontology Specifications, Knowledge acquisition, 1993

[7] Guarino, N., Formal ontology and information system, Proceedings of FOIS98, Trento, Italy, 6-8 June 1998. Amsterdam, IOS Press, pp. 3-15, 1998

[8] Lobonţiu, M. and Petrovan, A., A Product development ontology(1). Information integration concepts, Revista de Management şi Inginerie Economică, ISSN 1583-624X, 4(46) vol. 11, 2012, 43-56

[9] Matei, O., Defining an Ontology for the Radiograph Images Segmentation, 9th International Conference on Development and Application Systems, 2008

[10] Matei, O., Evolutionary Computation: Principles and Practices, Risoprint, 2008.

[11] Matei, O., Ontology-Based Knowledge Organization for the Radiograph Images Segmentation, Advances in Electrical and Computer Engineering, 8, 2008, No. 15

[12] Ming Gao, C. and Zhou, S., Automatic scene generating with fuzzy spatial relations, The Third International Conference on Digital Information and Communication Technology and its Applications (DICTAP2013). The Society of Digital Information and Wireless Communication, 2013. p. $144-147$

[13] Noy, N. F. and McGuinness, D. L., Ontology Development 101: A Guide to Creating Your First Ontology, Technical Report KSL0105, Stanford Knowledge Systems Laboratory, 2001

[14] Panagi, P., Dasiopoulou, S., Papadopoulos, G. T., Kompatsiaris, I. and Strintzis, M. G., A Genetic Algorithm Approach to Ontology-driven Semantic Image Analysis, Visual Information Engineering, 2006

[15] Petrovan, A. and Lobonţiu, M., Product development ontology. A case study, Quality Access to success, ISSN1582-2559, S5 vol. 13, 2012, 393-398

[16] Petrovan, A. and Lobonţiu, M., Broadening the Use of Product Development Ontology for One-off Products, Applied Mechanics and Materials, Vol. 371, 2013, 878-882

[17] Seversky, L. and Yin, L., Real-time automatic 3D scene generation from natural language voice and text descriptions, Proceedings of the 14th annual ACM international conference on Multimedia. ACM, 2006

[18] Sowa, J., Knowledge Representation: Logical, Philosophical and Computational Foundations, 1999

[19] Zook, A., Lee-Urban, S., Riedl, M., Holden, H., Sottilare, R. and Brawner, K., Automated Scenario Generation: Toward Tailored and Optimized Military Training in Virtual Environments, Proceedings of the International Conference on the Foundations of Digital Games. ACM, 2012. p. 164-171

TECHNiCAL UNIVERSITY OF CLUJ NAPOCA

AutOMATiOn DEPARTMENT

Memorandumului 28, 400114 Cluj Napoca, Romania

E-mail address: pdia17@yahoo.com

TeChNicAl University of Cluj NaPOCA

AutOMATION DEPARTMENT

Memorandumului 28, 400114 Cluj NaPOCA, Romania

E-mail address: taly_74@yahoo.com

TeChNicAl University of Cluj NaPOCA

AutOMATION Department

Memorandumului 28, 400114 Cluj Napoca, Romania

E-mail address: honoriu.valean@aut.utcluj.ro

Received: 30.07.2014; In revised form: 14.10.2014; Accepted: 15.10.2014

2010 Mathematics Subject Classification. 68T30.

Key words and phrases. Class, individual, ontology, relation, scene, DL Query. 